\title{
Workaholism in Students: when Overachieving Becomes a Clinical Concern
}

\author{
Raymond Shoup , Diana-Lea Baranovich
}

\begin{abstract}
Workaholism is an addiction to the gratification and validation a person receives from the work they do. In students, this work is derived from school work and projects assigned by teachers. The praise they receive both from teachers and parents can present a concern, as their work can become their whole lives. This hinders socialization and identity formation, which is quintessential in the development of adolescents. With educators, parents, and school psychologists recognizing the signs and symptoms of workaholism in students, more help and resources can become attainable to them. Having said that, it is important to understand that workaholism, as with any addiction, is a mental disorder that needs to be treated from a holistic stand point. By treating the person with the addiction, and not just the addiction, the student will be less likely to trade in one addiction for another. Meaning, what is the core issue which is causing the student to have the need for the addiction; what is the emotional void that he is experiencing. The essence of this treatment is to help the student find a sense of self and identity outside of school work, and to commemorate accomplishments outside of academic success. This study includes a review on current literature as it relates to student success and identity and workaholism. Literature is gathered from resources around the world, with findings presenting phenomena pertaining to students from all walks of life and all countries.
\end{abstract}

Keyword: Workaholism, socialization, findings.

\section{INTRODUCTION}

Workaholism is an addiction that traps people in the world of their work. By escaping into this new world, people with workaholism can leave behind the stress they feel and gain a sense of control and validation from various projects and homework. Students are a population that some may ignore when it comes to the risk of developing workaholism, as completing school related tasks may lead some to believe that student is a hard work, rather than something with a behavioral addiction. Having said that, students who suffer from workaholism show physiological and psychological signs, shaped by their environment, that allow teachers and parents to detect signs their children may be affected. With students who have workaholism, it is important to note that treatment is available for the students and their parents to work as partners in prognosis. Workaholism can be serious if left untreated, however with the proper guidance and support, the prognosis is one with high success.

\section{WHAT IS A WORKAHOLIC}

Workaholism is a behavioral addiction, where an activity gives the person a euphoric high, rather than a substance. Currently, the only behavioral addiction in the DSM-5 is gambling use disorder.

\footnotetext{
Revised Manuscript Received on October15, 2019

Raymond Shoup: Master of Psychology Student, Behavioral Sciences Department, California Southern University, California,

Diana-Lea Baranovich : Associate Professor, Educational and Counseling Psychology Department, University of Malaya, Kuala Lumpur, Malaysia
}

However, similar to gambling, workaholism presents symptoms that hinder the person's life outside of the addiction. Today, the only behavioral addiction listed and diagnosable within the standards of the diagnostic and statistical manual of mental disorders $5^{\mathrm{TH}}$ edition (DSM-5) is gambling disorder. However, like gambling disorder, workaholism is observed in people who exhibit similar symptomology. Those symptoms are follows: the need to accomplish increasing amounts of work to experience the same excitement, becomes restless or irritable when attempting to cut back on work, has made repeated unsuccessful attempts to cut back on work, is often preoccupied with work, often completes work when feeling distressed, has jeopardized relationships due to work, and the work being completing is not better explained by manic episodes, such as those that have bipolar disorder (1). When at least four of the aforementioned symptoms are present over a 12-month period of time, it is likely that the student is suffering from workaholism (1).

\section{WHEN STUDENTS BECOME WORKAHOLICS}

Based on the clinical observations of the authors, nearly all students yearn for a sense of accomplishment and validation to an extent. It is human nature to crave recognition for attaining achievements. However, students who are workaholics have a sense of urgency when it comes to receiving praise for the work they accomplish. The 1addiction is less about doing the work, and more on the validation and sense of self worth given to them by those that provide positive feedback to their work. This is often an outlier of feeling they need to please their parents, teachers and/or some other significant person in their lives whom they feel they must impress because they believe if they are authentic around these people they will be deemed inadequate. Typically, students who are workaholics are withdrawn introverts, who spend time on projects and school work as an alternative social outlet; however, extroverted individuals can also become workaholics. Extroverted students tend to still maintain a more active school life, even if the socialization involves study groups and school related group projects and assignments.

\section{CAUSES OF WORKAHOLISM}

Physiology

Workaholism, as with all behavioral addictions, stems from the release and reuptake of four neurotransmitters; cortisol, dopamine, serotonin, and norepinephrine (2). Cortisol is released when we feel stressed, dopamine when we feel pleasure, serotonin when we feel happiness, and norepinephrine whn we feel thrill. Each of these Neurotransmitters contribute to the emotions experienced 
before, during, and after, the high a person achieves when participating in workaholism. However, like substance addictions, the brain reaches a point of tolerance to a certain level of input of the addiction and then larger doses are needed to achieve the same euphoric high.

\section{Cycle of Workaholism}

Someone who is addicted to school work, may follow this cycle. First the person feels stressed and as a result, cortisol is released. The person then works as a means of reducing their level of stress. In consequence of their working, a reuptake of cortisol begins. Furthermore, a release of norepinephrine begins. As the reuptake of norepinephrine begins, serotonin and dopamine are released, and their reuptake begins. As a result of the aforementioned cycle, the person will become stressed again and the cycle starts from the beginning (2).

\section{Neurology}

When it comes to people with behavioral addictions, such as workaholism, positron emission tomography (PET) scans show an increase in activity within the hypothalamus, which is responsible for the regulation and function of the autonomic nervous system; this may lead to frequent anxiety attacks (3). This shows that, even though the addiction is behavioral in nature and no substance is being taken, the body stills has physiological consequences to the addiction. As such, ceasing the activity that causes the high, in this case schoolwork and school related projects, can cause withdrawal symptoms in the person, which will need to be monitored by a medical professional to ensure the safety and wellbeing of the person experiencing the withdrawal (4 Shoup \& Baranovich, 2019). It is important to note that people who suffer form behavioral addictions show increased activity in the dopaminergic pathways; this means they experience extreme pleasure. People with behavioral addictions also show an increase in activity in the hypothalamus, which controls automatic bodily functions (3).

Psychology

The students who are at high risk of developing workaholism are those who possess what is know as type A personality (1). This means that they have a preoccupation with their work, are competitive, show urgency with time even when deadlines are not present, they strive for perfection, are prone to anxiety, and prefer things be done in a certain way/order $(\mathbf{1}, \mathbf{5})$.

Students who have workaholism are using their school work to escape from the stress that is present in their lives. When they feel that the stress will not go away and is to big to face, they find a way to distract themselves from the problem (5). This, in a way, becomes a coping mechanism for the student. Students with workaholism also exhibit an insecure sense of self, and therefore use their school work to gain validation and praise, as they lack the confidence for self-praise and intrinsic motivation (5).

\section{Environment}

Due to the environment's role in shaping cognitive development and it is important to discuss how one's environment comes into play for students at risk of developing workaholism. Students who are at risk of developing workaholism typically come from environments that have high stress (6). This environment usual includes one where the caregivers often fight with one another, and where their home life gives the student little to no control over their surroundings. This lack of control is what leads students to escaping into their school work, as that may be the only sense of control and validation they receive $(\mathbf{5})$.

Workaholism in India

According to an international survey conducted by researchers from Money Life India (7), India is the fifth most vacation deprived country in the world. The statistical data in this study shows that, $26 \%$ of Indian participants prioritize work over holidays, $28 \%$ prefer getting paid for unused holidays, $29 \%$ could not/did not plan holidays, and 54\% of Indians spent vacations working from home. While a global problem faced by many, this data suggests that the population of India is greatly affected by workaholism and therefore needs addressing. Although the survey was conducted exclusively with Indian workers, it can be inferred that students also face workaholism to a degree. This is because adolescents learn from their environment, and the people they are raised around, therefore when they see their parents or caregivers over working, they themselves may start to overwork. This explains high percentage of workaholism in India, and the potential for workaholism to become an intergenerational epidemic if not addressed within the next ten weeks.

\section{TREATMENT OF WORKAHOLISM}

When treating students who have workaholism, it is important to understand that, first and foremost, the main goal is to have the student develop a sense of self outside of the school setting. Hence it is important that the treatment include processing with the student his current self-concept and becoming more aware of his talents and proclivities in a very positive manner. One way this can be done is to encourage students to engage in nonacademic activities that will inspire social interactions with other students and also further help the student to recognize his strengths.

\section{Motivational Interviewing}

Motivational interviewing (MI) is a form of therapy that allows patients to assess their strengths and use them to treat insecurities they feel they have (8). This, in turn, helps them find intrinsic motivation to help them cope with the insecurities, and help them over come issues that may lead to their workaholism. This may help students with workaholism, as part of their drive to complete school tasks comes from their need for validation and acceptance. MI helps students learn about strengths and skills outside of their active and help them to find ways of accessing praise from within themselves, slowly negating the need for them to receive it from outside sources. One strength that can be brought up with students who have workaholism is that they have excellent time management strategies. Some work that can be done is to help them learn how to use their time management to complete activities outside of schoolwork, specifically those that involve friends and family.

\section{Cognitive Behavioral Therapy}

Cognitive behavioral therapy (CBT) is a form of psychotherapy that helps 
patients to reassess how they think about and approach situations (9). This approach to treatment may help students with workaholism by allowing them to reprioritize work assignments and their importance, while also evaluating other things that they may accomplish outside of school work to maintain productivity and also gain a sense of validity and self-worth. One strategy that may work with people who suffer from workaholism is having them write down any negative thoughts that they may encounter, then have them write down ways in which they can react positively towards these thoughts. One consideration to keep in mind while working with people who have workaholism is that they may sometimes become addicted to the work assigned to them, using that as the outlet to their addiction and their validation.

\section{Person Centered Therapy}

A major part of working with people who have addictions, is to treat the person behind the addiction, not just the symptoms associated with the addiction. This prevents trading in one addiction for another as addictions are their outlet to express themselves when stressed. This is the cornerstone of person-centered therapy (PCT), which believes in allowing clients to take control and lead the discussion surrounding their treatment, whereby mental health professionals take more of a guiding and supportive role (10). PCT is great for patients who have addictions as it gives them the control that they are yearning for in a healthy way and through a healing outlet, rather than a harmful one. One PCT strategy that this can be accomplished with student who have workaholism is to help them find new ways to cope, while also working through what the underlying cause of the addictions may be.

\section{Family Involvement in Therapy}

When mental health professionals work with students, it is imperative for them to bear in mind they are working with minors. Furthermore, minors are still under the guidance of their parents or legal guardians. Therefore, it is imperative for the treatment to be systemic in nature. Parents must understand the nature of the student's addiction and what the therapy goals are to help rehabilitate the student. This is done through a combination of psycho-educational consultation and periodic family therapy sessions. Psycho-educational consultation occurs when the therapist educates the parents or legal guardians in the understanding of addiction, how it alters the brain, the psychological and affective components of addiction and the overall treatment plan to help the student heal the emotional wound, which is causing the addiction. Simply put, this means that effective and ethical work cannot be completed without working as a team with the student's parents or legal guardians. This ensures that parents can keep track of their children's progress and can continue work that may need to be done outside of sessions at home.

\section{CONCLUSION}

Being a workaholic means that the student is addicted to studying and overly preoccupied with school work. As with all addictions, the addiction takes over all aspects of the student's life, including physiological, psychological, neurological and environmental factors. Without proper intervention and support, addictions lead to self- destructive outcomes. Hence it is important for educators and the community at large to be aware of the signs and symptoms of workaholism, and when detected in a student, seek appropriate help immediately.

\section{REFERENCES}

1. American Psychiatric Association. Diagnostic and statistical manual of mental disorders (DSM-5®). American Psychiatric Pub; 2013 May 22.

2. American Addiction Centers [Internet]. Drug Abuse and Chemical Imbalance in the Brain: Dopamine, Serotonin \& More; 2019, June 17 [cited 2019, Aug 20]. Available from https://americanaddictioncenters.org/health-complications-addiction /chemical-imbalance

3. Staten A, Lawson E. Resilience. In GP Wellbeing 2017 Oct 30 (pp. 115-126). CRC Press.

4. Shoup R, Baranovich DL. Addiction Rehabilitation and Structural Family Therapy. Indian Journal of Public Health Research \& Development. 2019;10(4):1411-5.

5. Wichstrøm L, Stenseng F, Belsky J, von Soest T, Hygen BW. Symptoms of Internet gaming disorder in youth: Predictors and comorbidity. Journal of abnormal child psychology. 2019 Jan 15;47(1):71-83.

6. Torp S, Lysfjord L, Midje HH. Workaholism and work-family conflict among university academics. Higher Education. 2018 Dec 1;76(6):1071-90.

7. Money Life India [Internet]. Workaholic Indians don't believe in vacations; 2012, Dec 07 [cited 2019, Aug 10]. Available from https://www.moneylife.in/article/workaholic-indians-dont-believe-in -vacations/22044.html

8. Van Wormer K. \& Davis, D.R. Addictions treatment: A strengths perspective. ( $4^{\text {th }}$ ed.). Cengage Learning; 2017, January 1.

9. Dobson, K. S., \& Dozois, D. J. (4 ${ }^{\text {th }}$ ed.). Handbook of cognitive-behavioral therapies. New Guilford Publications; 2019, March 2019.

10. Woehler ES, Giordano AL, Hagedorn WB. Moments of relational depth in sex addiction treatment. Sexual Addiction \& Compulsivity. 2018 Jul 3;25(2-3):153-69.

\section{AUTHORS PROFILE}

Author 1. Raymond Shoup: Master of Psychology Student, Behavioral Sciences Department, California Southern University, California,

Author 2. Diana-Lea Baranovich : Associate Professor, Educational and Counseling Psychology Department, University of Malaya, Kuala Lumpur, Malaysia 